\title{
Percentile reference curves for normal pancreatic dimensions in Indian children
}

\author{
Dhanraj S Raut, Dhananjay V Raje1, Vithalrao P Dandge, Dinesh Singh² \\ Department of Pediatrics, NKP Salve Institute of Medical Sciences, ${ }^{2}$ Spiral CT Scan and Diagnostic Center, Nagpur, \\ 'Data Analysis Division, MDS Bio-Analytics Pvt. Ltd., Mumbai, Maharashtra, India \\ Correspondence: Dr. Dhanraj S Raut, Department of Pediatrics, NKP Salve Institute of Medical Sciences, Nagpur, Maharashtra, India. \\ E-mail: 147dsr@gmail.com
}

\begin{abstract}
Objectives: This study aims at determining the normal pancreatic dimensions in pediatric age groups considering demographic parameters and thus developing percentile reference curves for normal pancreatic dimensions in Indian children. Setting and Design: It is a cross-sectional study. Materials and Methods: A hospital-based cross-sectional study was planned at a children hospital during July 2016-December 2017, in which the pancreatic dimensions of 1078 normal children in the age range of 1 month to 19 years were obtained through abdominal ultrasonography (USG). The demographic details like age and gender were obtained for each child. Statistical Analysis Used: Percentile reference curves were obtained with reference to age for each gender type independently. Generalized additive models for location, scale, and shape were used to obtain percentile plots for each pancreatic part. Results: The mean age of children was $6.65 \pm 4.43$ years and the male-to-female ratio was $1.63: 1$. The head, body, and tail dimensions increased with the age. For head, up to $25^{\text {th }}$ percentile, the curves were similar for both genders, while subsequent curves were higher in males as compared to females. Similar was the observation for body of pancreas. For tail, up to $75^{\text {th }}$ percentile, the curves were similar for both genders. Conclusion: The normal ranges can be supportive in diagnosis of illness related to pancreas. The dimensions within $5-95^{\text {th }}$ percentile along with iso-echogenicity can be regarded as normal, while the dimensions beyond these limits along with change of echogenicity can be suspected for pancreatic disorders.
\end{abstract}

Key words: Generalized additive models; pancreas; percentile curves

\section{Introduction}

The dimensions of abdominal organs like kidney, spleen, and pancreas have potential significance. A multitude of medical conditions is associated with the changes in the volume and size of these organs. The pancreas continues to grow until approximately the age of 25 years. Normal pancreas across individuals seems to show a great variation in size. ${ }^{[1]}$ The assessment of normal pancreatic size is an integral part of the evaluation of pancreatic diseases for both diagnostic and prognostic purposes.

\begin{tabular}{|c|c|}
\hline \multicolumn{2}{|c|}{ Access this article online } \\
\hline Quick Response Code: & \\
\hline \multirow{2}{*}{ 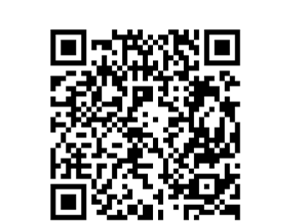 } & $\begin{array}{l}\text { Website: } \\
\text { www.ijri.org }\end{array}$ \\
\hline & $\begin{array}{l}\text { DOI: } \\
\text { 10.4103/ijri.IJRI_189_18 }\end{array}$ \\
\hline
\end{tabular}

Currently, sonography is used as a radiologic noninvasive procedure of choice in the examination of children with symptoms referable to pancreas. ${ }^{[2-11]}$ The most widely used criteria for determining the presence or absence of pancreatic diseases are based on alterations of pancreatic size, contour, and echotexture. Hence, it becomes important to evaluate the normal size, morphology, and echogenicity of pancreas at various stages of development. ${ }^{[3,4]}$ Data on normal pancreatic dimensions are available on western population. ${ }^{[3,4]}$ The question is, whether these can be extrapolated to Indian children,

This is an open access journal, and articles are distributed under the terms of the Creative Commons Attribution-NonCommercial-ShareAlike 4.0 License, which allows others to remix, tweak, and build upon the work non-commercially, as long as appropriate credit is given and the new creations are licensed under the identical terms.

For reprints contact: reprints@medknow.com

Cite this article as: Raut DS, Raje DV, Dandge VP, Singh D. Percentile reference curves for normal pancreatic dimensions in Indian children. Indian J Radiol Imaging 2018;28:442-7. 
as there is no reference for pancreatic size in the Indian population.

The main purpose of this study was to determine the variability of anteroposterior (AP) diameters of head, body, and tail of pancreas ultrasonically by considering demographic and anthropometric parameters and develop percentile reference values for normal pancreatic dimensions for children under Indian context.

\section{Materials and Methods}

This was a cross-sectional study in which 1078 children in the age range of 1 month to 19 years attending a pediatric center during the period July 2016 to December 2017 were considered. The inclusion criteria were (a) normal healthy siblings of patients attending outpatient department and those visiting for vaccination, and (b) those children without any clinical or laboratory evidence of pancreatic disorder, like acute pancreatitis, which is most common among pancreatic disorders. Children with protein energy malnutrition (according to Indian Academy of Pediatrics classification) ${ }^{[12]}$ type I diabetes mellitus, ${ }^{[13]}$ cystic fibrosis, ${ }^{[14]}$ premature infants ${ }^{[3]}$ and clinical or laboratory evidence of hepatic diseases, ${ }^{[3,15]}$ and obesity, ${ }^{[16]}$ where echogenicity gets altered, were excluded from the study. Proper consent was obtained from accompanying parents for ultrasonography (USG) evaluation, and the protocol was approved by the institutional ethics committee. A single radiological center from the city was identified for abdominal sonography. Parameters like age, gender, height, and weight of the subjects were recorded at the time of examination. The Goldtech instrument from Precision electronic instruments company, New Delhi was used for weighing infants, while older children were measured using instrument by Detecto Medic Scales Inc., USA. Weights were recorded to the nearest $100 \mathrm{~g}$. The supine lengths were measured on an infantometer in children below 2 years and standing height was measured on stadiometer in children above 2 years to the nearest $1 \mathrm{~mm}$.

\section{Abdominal sonography}

A single qualified radiologist with over 25 years of experience was involved in the USG evaluations. Observations were repeated thrice to account for the intra-observer reliability. The average of three observations was reported for analysis. While selecting the abdominal sonogram, emphasis was on pancreatic dimensions, shape, echogenicity, calcification, and the status of the main pancreatic duct. The echogenicity of pancreas was compared to the texture of the region in the left lobe of liver. The sonographic examination was mostly conducted in morning hours, in supine position to eliminate the difference of dimensions in different positions. ${ }^{[4,15]}$ Some children required nearly $200-400 \mathrm{ml}$ of water to drink to delineate the image of pancreas, which could have been obscured by the gas in the stomach. No other pretreatment was used. ${ }^{[4,15]}$ A well-calibrated Sonoacc X8 Medison-Korean (SAX8) with 3.5, 5.0, and 7.5 MHz sector electronic probes properly focused on the pancreas after adequate gain setting was used during the course of study. A sample abdominal USG showing pancreatic parts with L1 vertebra is shown in Figure 1.

Anatomical landmarks for head, body, and tail of pancreas The diameters of head, body, and tail were measured perpendicular to the long axis of the organ. A reliable diagnosis depends on the analysis of adjacent structures of pancreas. For measuring head of pancreas, duodenum, which envelops the lateral and caudal contour of the head, was taken as a landmark for measurement. ${ }^{[3,4]}$ The superior mesenteric artery and splenic vein serve as important landmarks, for localization of the body of pancreas. ${ }^{[3,4]}$ The splenic vein has a major contribution for localizing the tail of pancreas. ${ }^{[3]}$

The maximum AP diameters of head, body, and tail of pancreas were measured on transverse/oblique images. If pancreas was oriented transversely across the abdomen, the entire gland could be seen in one image. However, the pancreas often had varying degree of obliquity, with the tail lying more cranial than the head and body. In such cases, multiple images were necessary to demonstrate the entire gland. ${ }^{[3]}$ Pancreatic echogenicity was determined by comparison with the adjacent liver at a similar depth on both transverse and longitudinal views. Pancreatic echogenicity was categorized as less than, equal to, or greater than liver echogenicity. ${ }^{[3,17]}$ The data on dimensions were analyzed along with anthropometric data using robust statistical methods.

\section{Statistical methods}

The descriptive statistics like mean and standard deviation of the dimensions of head, body, and tail were obtained for different age, height, and weight categories. The percentile curves for the three pancreatic parts were obtained as a function of age using generalized additive models for

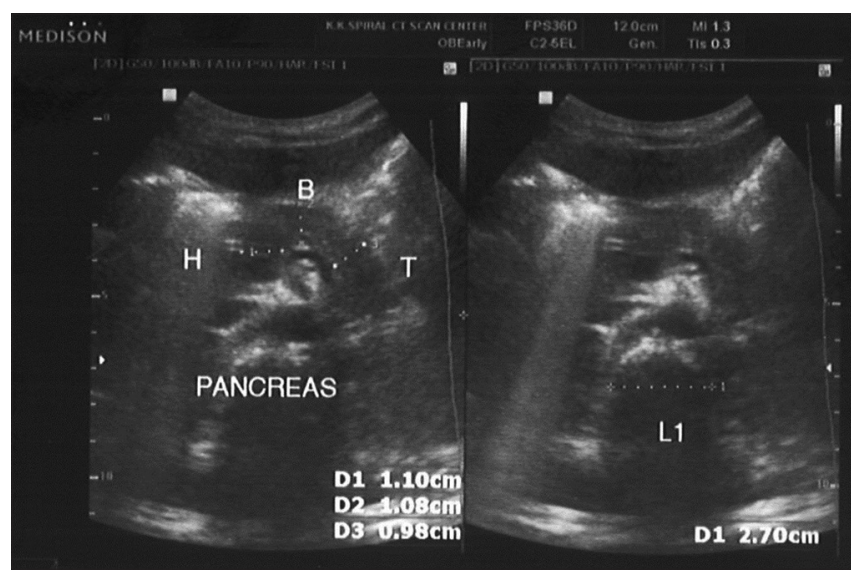

Figure 1: A sample abdominal USG showing pancreatic parts with L1 vertebra 
location, scale, and shape (GAMLSS) stratified by gender. GAMLSS are semi-parametric regression models, which require a parametric distribution assumption for response variable, and it is "semi" because modeling parameters of the distribution may involve nonparametric smoothing functions. ${ }^{[18]}$ GAMLSS are more suited for modeling response variable wherein the shape and scale of the distribution of response variable change with explanatory variable. In the present study, each pancreatic dimension was referred as response variable, while age was treated as explanatory variable. GAMLSS models four parameters as a function of explanatory variable: the median, the coefficient of variation, the skewness, and the kurtosis of the best distribution. Different distributions like the Box-Cox power exponential, the Box-Cox $t$, the Box-Cox Cole, and Green distribution were fitted to the distribution of each pancreatic dimension. The goodness of fit was evaluated using GAIC $(k)$ criterion. Finally, the selected models for each pancreatic dimension were used to calculate the curves for $5^{\text {th }}, 10^{\text {th }}, 25^{\text {th }}, 50^{\text {th }}, 75^{\text {th }}$, and $95^{\text {th }}$ percentiles. The curves were obtained separately for males and females according to age. All the analyses were performed using GAMLSS package from R - 3.4.3 (R Core Team, Vienna, Austria).

The percentile reference curves were digitized wherein the inputs required are the age of child and the pancreatic dimensions. A point appears on the reference curves for head, body, and tail indicating the percentile limits for each pancreatic dimension. The application is available at https://mdsclin.in and can be accessed by keying pancreas as username and password.

\section{Results}

The mean age of 1078 children at the time of USG was $6.65 \pm 4.43$ years and the male-to-female ratio was 1.63:1. The length/height of subjects ranged from 43 to $166 \mathrm{~cm}$, while weight ranged from 2.6 to $65 \mathrm{~kg}$ and body surface area ranged from 0.18 to $1.54 \mathrm{~m}^{2}$. The descriptive statistics like mean and standard deviation for each pancreatic section according to age, height, and weight are given in Table 1. It shows that the mean dimension for each part increased with the increasing age. Moreover, the standard deviation also showed increasing trend with age, indicating heteroscedasticity in the measurements with age. Studentized Breusch-Pagan method revealed significant heteroscedasticity in head measurements, with a $P$ value of 0.0003 , while for body and tail, heteroscedasticity was insignificant across age. Further, mean dimension of each part increased with the increasing height, while heteroscedasticity was statistically insignificant for all the three measurements. For weight, the mean dimension for all the three sections increased with the increasing weight, while heteroscedasticity was statistically insignificant.

The percentile reference values for head measurement according to age and gender are shown in Table 2 and depicted in Figure 2. The head dimension increased with age

Table 1: Dimensions of pancreatic part according to age, height, and weight observed in three studies

\begin{tabular}{|c|c|c|c|c|c|c|c|c|c|c|c|c|}
\hline \multirow[t]{2}{*}{ Characteristic } & \multirow[t]{2}{*}{ Levels } & \multirow[t]{2}{*}{$n$} & \multicolumn{3}{|c|}{ Present study ( $n=1078)$} & \multirow[t]{2}{*}{$n$} & \multicolumn{3}{|c|}{ Study by Siegel et al. $(n=273)$} & \multirow[t]{2}{*}{$n$} & \multicolumn{2}{|c|}{ Study by Ueda $(n=93)$} \\
\hline & & & Head & Body & Tail & & Head & Body & Tail & & Head & Body \\
\hline \multirow[t]{5}{*}{ Age } & $<1$ month & 30 & $0.53 \pm 0.13$ & $0.49 \pm 0.11$ & $0.51 \pm 0.13$ & 15 & $1.0 \pm 0.4$ & $0.6 \pm 0.2$ & $1.0 \pm 0.4$ & & & \\
\hline & 1 month-1 year & 73 & $0.74 \pm 0.19$ & $0.70 \pm 0.15$ & $0.71 \pm 0.18$ & 23 & $1.5 \pm 0.5$ & $0.8 \pm 0.3$ & $1.2 \pm 0.4$ & 5 & $0.7 \pm 0.2$ & $0.6 \pm 0.1$ \\
\hline & $1-5$ years & 351 & $0.93 \pm 0.30$ & $0.86 \pm 0.23$ & $0.91 \pm 0.26$ & 49 & $1.7 \pm 0.3$ & $1.0 \pm 0.2$ & $1.8 \pm 0.4$ & 35 & $1.5 \pm 0.2$ & $0.8 \pm 0.2$ \\
\hline & $5-10$ years & 393 & $1.07 \pm 0.31$ & $0.98 \pm 0.23$ & $1.05 \pm 0.25$ & 69 & $1.6 \pm 0.4$ & $1.0 \pm 0.3$ & $1.8 \pm 0.4$ & 27 & $1.7 \pm 0.3$ & $0.9 \pm 0.2$ \\
\hline & $10-19$ years & 231 & $1.18 \pm 0.34$ & $1.04 \pm 0.23$ & $1.11 \pm 0.25$ & 117 & $2.0 \pm 0.5$ & $1.1 \pm 0.3$ & $2.0 \pm 0.4$ & 26 & $1.8 \pm 0.2$ & $0.9 \pm 0.1$ \\
\hline \multirow[t]{9}{*}{ Height $(\mathrm{cm})$} & $<90$ & 298 & $0.81 \pm 0.25$ & $0.76 \pm 0.21$ & $0.79 \pm 0.25$ & & & & & & $1.1 \pm 0.4$ & $0.7 \pm 0.1$ \\
\hline & $90-99$ & 75 & $0.99 \pm 0.30$ & $0.90 \pm 0.23$ & $0.96 \pm 0.25$ & & & & & & $1.5 \pm 0.2$ & $0.8 \pm 0.1$ \\
\hline & $100-109$ & 147 & $1.01 \pm 0.32$ & $0.97 \pm 0.26$ & $0.99 \pm 0.25$ & & & & & & $1.6 \pm 0.2$ & $0.9 \pm 0.1$ \\
\hline & $110-119$ & 117 & $1.14 \pm 0.32$ & $1.02 \pm 0.25$ & $1.09 \pm 0.26$ & & & & & & $1.6 \pm 0.2$ & $0.8 \pm 0.1$ \\
\hline & $120-129$ & 129 & $1.10 \pm 0.32$ & $0.98 \pm 0.20$ & $1.09 \pm 0.26$ & & & & & & $1.7 \pm 0.3$ & $0.8 \pm 0.2$ \\
\hline & $130-139$ & 129 & $1.12 \pm 0.29$ & $1.01 \pm 0.22$ & $1.06 \pm 0.25$ & & & & & & $1.6 \pm 0.4$ & $1.0 \pm 0.1$ \\
\hline & $140-149$ & 93 & $1.11 \pm 0.39$ & $1.01 \pm 0.23$ & $1.07 \pm 0.26$ & & & & & & $1.7 \pm 0.2$ & $0.9 \pm 0.2$ \\
\hline & $150-159$ & 44 & $1.21 \pm 0.41$ & $1.09 \pm 0.29$ & $1.11 \pm 0.25$ & & & & & & $1.8 \pm 0.2$ & $1.0 \pm 0.1$ \\
\hline & $160-169$ & 46 & $1.11 \pm 0.25$ & $1.02 \pm 0.23$ & $1.13 \pm 0.25$ & & & & & & $2.0 \pm 0.2$ & $1.0 \pm 0.1$ \\
\hline \multirow[t]{7}{*}{ Weight (kg) } & $1-10$ & 205 & $0.79 \pm 0.26$ & $0.73 \pm 0.22$ & $0.76 \pm 0.24$ & & & & & & & \\
\hline & $10-20$ & 402 & $0.99 \pm 0.30$ & $0.91 \pm 0.23$ & $0.98 \pm 0.25$ & & & & & & & \\
\hline & $20-30$ & 264 & $1.11 \pm 0.31$ & $1.00 \pm 0.23$ & $1.08 \pm 0.25$ & & & & & & & \\
\hline & $30-40$ & 106 & $1.11 \pm 0.30$ & $1.01 \pm 0.20$ & $1.07 \pm 0.26$ & & & & & & & \\
\hline & $40-50$ & 56 & $1.27 \pm 0.42$ & $1.11 \pm 0.30$ & $1.17 \pm 0.25$ & & & & & & & \\
\hline & $50-60$ & 37 & $1.31 \pm 0.33$ & $1.09 \pm 0.26$ & $1.17 \pm 0.27$ & & & & & & & \\
\hline & $60-70$ & 8 & $1.18 \pm 0.37$ & $0.89 \pm 0.13$ & $0.98 \pm 0.31$ & & & & & & & \\
\hline
\end{tabular}


Raut, et al.: Reference curves for normal pancreas

Table 2: Percentile reference values for head of pancreas using generalized additive models for location, scale, and shape in normal Indian children

\begin{tabular}{|c|c|c|c|c|c|c|c|c|c|c|c|c|c|}
\hline \multirow[t]{2}{*}{ Age (years) } & \multicolumn{6}{|c|}{ Percentile for male } & \multirow[t]{2}{*}{ Age (years) } & \multicolumn{6}{|c|}{ Percentile for female } \\
\hline & 5 & 10 & 25 & 50 & 75 & 95 & & 5 & 10 & 25 & 50 & 75 & 95 \\
\hline $0.01-1$ & 0.50 & 0.54 & 0.63 & 0.77 & 0.94 & 1.21 & $0.01-1$ & 0.45 & 0.48 & 0.57 & 0.75 & 0.98 & 1.26 \\
\hline $1-3$ & 0.56 & 0.61 & 0.72 & 0.88 & 1.08 & 1.40 & $1-3$ & 0.51 & 0.56 & 0.67 & 0.86 & 1.13 & 1.51 \\
\hline $3-6$ & 0.62 & 0.68 & 0.80 & 0.98 & 1.21 & 1.57 & $3-6$ & 0.58 & 0.63 & 0.75 & 0.95 & 1.21 & 1.64 \\
\hline $6-9$ & 0.66 & 0.73 & 0.86 & 1.06 & 1.30 & 1.69 & $6-9$ & 0.64 & 0.69 & 0.81 & 1.01 & 1.26 & 1.68 \\
\hline $9-12$ & 0.70 & 0.77 & 0.91 & 1.12 & 1.38 & 1.79 & $9-12$ & 0.68 & 0.74 & 0.87 & 1.05 & 1.29 & 1.71 \\
\hline $12-15$ & 0.73 & 0.80 & 0.95 & 1.18 & 1.45 & 1.88 & $12-15$ & 0.72 & 0.78 & 0.91 & 1.09 & 1.31 & 1.74 \\
\hline $15-19$ & 0.76 & 0.84 & 1.01 & 1.24 & 1.53 & 1.99 & $15-19$ & 0.76 & 0.83 & 0.95 & 1.13 & 1.34 & 1.76 \\
\hline
\end{tabular}
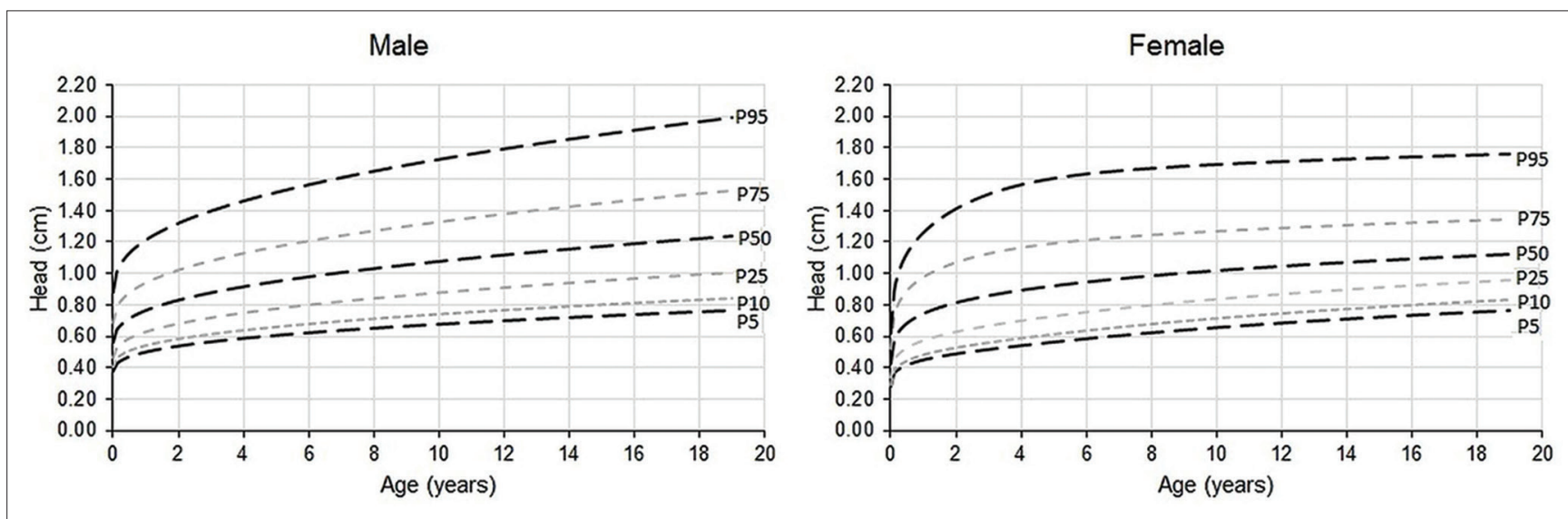

Figure 2: Percentile curves of head of pancreas according to gender in normal Indian children

for both males and females. The plots revealed that the $5^{\text {th }}$, $10^{\text {th }}$, and $25^{\text {th }}$ percentile curves for both males and females were almost the same. However, $50^{\text {th }}, 75^{\text {th }}$, and $95^{\text {th }}$ percentile curves for males were higher than that of females, and the difference was wider for age greater than 12 years. For instance, the $50^{\text {th }}$ percentile value for age group 9-12 years in males was 1.12, which was higher than that of females with value 1.05 . For age group $15-19$ years, $50^{\text {th }}$ percentile value was 1.24 in males, which was further higher than that of females with 1.13. The difference of centile values of head between males and females ranged between 0.01 and 0.23.

On similar lines, the percentile reference values were obtained for body of pancreas as shown in Table 3 and the curves are shown in Figure 3. The body dimension also increased with age for both males and females. The percentile values for males were marginally higher as compared to females in each group as evident from the table and also evident through figure. For instance, the $50^{\text {th }}$ percentile value for age group 9-12 years in males was 1.01, which was higher than females with value of 0.98 . The difference of centile values between males and females ranged between 0.01 and 0.08 .

Table 4 provides the percentile reference values for tail of pancreas and Figure 4 shows the percentile curves as per gender. The percentile values increased with the increasing age for both gender types. Up to $75^{\text {th }}$ percentile, the increase in dimension with age was almost similar for both males and females. However, beyond 6 years, the $95^{\text {th }}$ percentile values for females were higher than that of males. The difference of centile values between males and females ranged between 0.01 and 0.16 .

\section{Discussion}

The dimensions of normal pancreas show great variation, ${ }^{[1]}$ as observed in the present study. The study revealed that mean dimension of head and tail for the study group was smaller than that reported by Seigel et al., ${ }^{[3]}$ while the mean dimension for body was nearly similar. The dimensions of head and tail were nearly same in each age group, which corroborates with the findings by Seigel et al. ${ }^{[3]}$ Normal dimensions described by $\mathrm{Ueda}^{[4]}$ in short axis for head are more in all age groups as compared to those observed in this study; however, the observations for body were quite close with his study. Normal dimensions of each part were also studied as a function of height. The mean diameter of head was smaller compared to the diameter on short axis, as reported by Ueda, while the mean diameter of body observed in the study was quite close to that reported by Ueda. ${ }^{[4]}$ The reason for this discrepancy is not clear but may reflect the difference of physical constitution according to races in same age groups, and also perhaps the influence 
Raut, et al.: Reference curves for normal pancreas

Table 3: Percentile reference values for body of pancreas using generalized additive models for location, scale, and shape in normal Indian children

\begin{tabular}{|c|c|c|c|c|c|c|c|c|c|c|c|c|c|}
\hline \multirow[t]{2}{*}{ Age (years) } & \multicolumn{6}{|c|}{ Percentile for male } & \multirow[t]{2}{*}{ Age (years) } & \multicolumn{6}{|c|}{ Percentile for female } \\
\hline & 5 & 10 & 25 & 50 & 75 & 95 & & 5 & 10 & 25 & 50 & 75 & 95 \\
\hline $0.01-1$ & 0.48 & 0.54 & 0.63 & 0.74 & 0.87 & 1.07 & $0.01-1$ & 0.44 & 0.49 & 0.58 & 0.70 & 0.84 & 1.12 \\
\hline $1-3$ & 0.57 & 0.62 & 0.71 & 0.84 & 0.98 & 1.21 & $1-3$ & 0.52 & 0.57 & 0.67 & 0.80 & 0.97 & 1.28 \\
\hline $3-6$ & 0.63 & 0.69 & 0.79 & 0.91 & 1.06 & 1.33 & $3-6$ & 0.58 & 0.64 & 0.75 & 0.89 & 1.06 & 1.37 \\
\hline $6-9$ & 0.68 & 0.73 & 0.83 & 0.97 & 1.13 & 1.41 & $6-9$ & 0.64 & 0.69 & 0.80 & 0.94 & 1.11 & 1.42 \\
\hline $9-12$ & 0.72 & 0.77 & 0.87 & 1.01 & 1.18 & 1.48 & $9-12$ & 0.68 & 0.73 & 0.84 & 0.98 & 1.15 & 1.45 \\
\hline $12-15$ & 0.75 & 0.80 & 0.91 & 1.05 & 1.22 & 1.54 & $12-15$ & 0.71 & 0.77 & 0.88 & 1.02 & 1.19 & 1.48 \\
\hline $15-19$ & 0.78 & 0.84 & 0.94 & 1.09 & 1.26 & 1.60 & $15-19$ & 0.75 & 0.81 & 0.92 & 1.06 & 1.23 & 1.52 \\
\hline
\end{tabular}

Table 4: Percentile reference values for tail of pancreas using generalized additive models for location, scale, and shape in normal Indian children

\begin{tabular}{|c|c|c|c|c|c|c|c|c|c|c|c|c|c|}
\hline \multirow[t]{2}{*}{ Age (years) } & \multicolumn{6}{|c|}{ Percentile for male } & \multirow[t]{2}{*}{ Age (years) } & \multicolumn{6}{|c|}{ Percentile for female } \\
\hline & 5 & 10 & 25 & 50 & 75 & 95 & & 5 & 10 & 25 & 50 & 75 & 95 \\
\hline $0.01-1$ & 0.50 & 0.55 & 0.65 & 0.77 & 0.92 & 1.16 & $0.01-1$ & 0.48 & 0.52 & 0.60 & 0.74 & 0.91 & 1.13 \\
\hline $1-3$ & 0.58 & 0.64 & 0.75 & 0.89 & 1.05 & 1.33 & $1-3$ & 0.56 & 0.61 & 0.71 & 0.86 & 1.04 & 1.32 \\
\hline 3-6 & 0.65 & 0.71 & 0.83 & 0.98 & 1.15 & 1.44 & $3-6$ & 0.62 & 0.68 & 0.80 & 0.96 & 1.15 & 1.47 \\
\hline $6-9$ & 0.70 & 0.77 & 0.89 & 1.04 & 1.21 & 1.50 & $6-9$ & 0.67 & 0.74 & 0.86 & 1.02 & 1.21 & 1.57 \\
\hline $9-12$ & 0.74 & 0.81 & 0.93 & 1.08 & 1.26 & 1.55 & $9-12$ & 0.70 & 0.78 & 0.91 & 1.08 & 1.27 & 1.65 \\
\hline $12-15$ & 0.77 & 0.84 & 0.97 & 1.12 & 1.30 & 1.59 & $12-15$ & 0.73 & 0.82 & 0.96 & 1.12 & 1.31 & 1.71 \\
\hline $15-19$ & 0.81 & 0.88 & 1.01 & 1.16 & 1.34 & 1.63 & $15-19$ & 0.77 & 0.86 & 1.01 & 1.17 & 1.35 & 1.79 \\
\hline
\end{tabular}

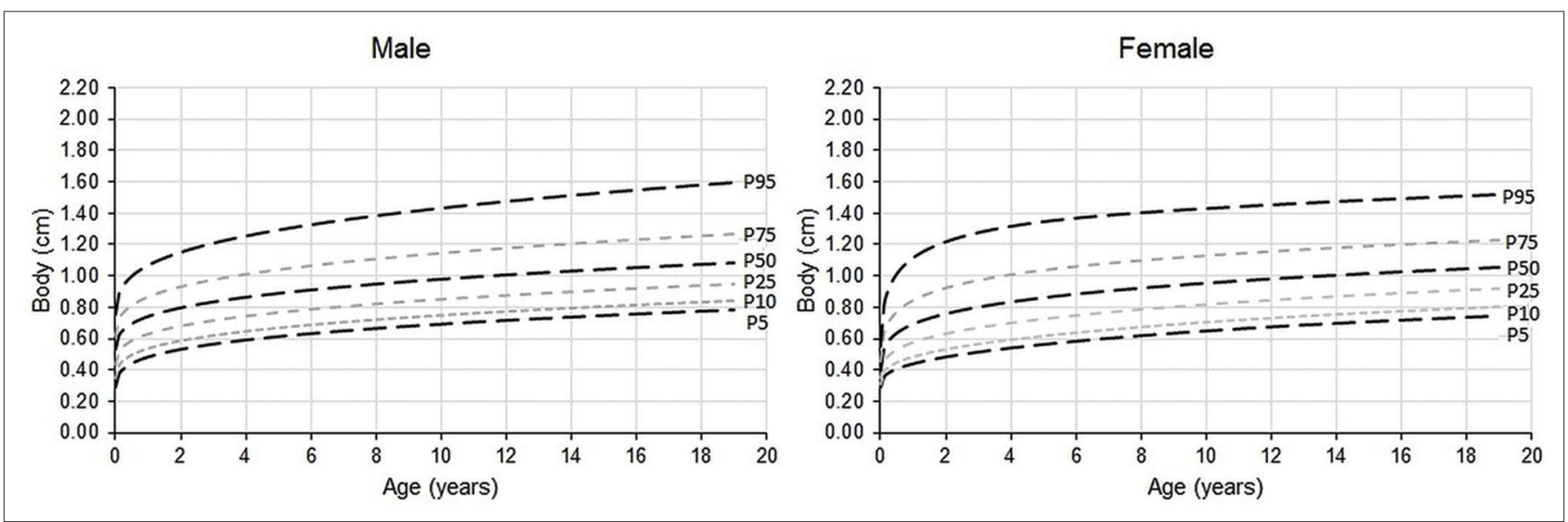

Figure 3: Percentile curves for body of pancreas according to gender in normal Indian children

of genetic and environmental factors across population. ${ }^{[1]}$ Pancreatic iso-echogenicity was observed in all the studied cases. Hypoechogenicity was reported in $10 \%$ cases by Seigal et al. ${ }^{[3]}$

This study provides age- and gender-specific percentile reference values for the three pancreatic parts based on a sample of 1078 normal children. At present, such data are not available under Indian context. The age-specific percentile values of head and body for males were higher than that of females. However, for tail, the values were close for gender types till $75^{\text {th }}$ percentile, but differed in $95^{\text {th }}$ percentile, and were higher for females as compared to males.

\section{Utility of Percentile Curves}

The derived centile plots for three pancreatic parts can be referred by radiologists or clinicians to opine about the normal or abnormal dimensions of pancreas in children. For a new subject with specific age and gender, the pancreatic dimensions as obtained through USG can be mapped onto the respective percentile plots and may be interpreted.

Moreover, certain disease conditions are known to influence the dimensions of pancreas. Diseases like acute pancreatitis result in the enlargement of pancreatic size, while some may diminish in size, as observed in cystic fibrosis. USG findings under disease condition and the findings when the patient is 

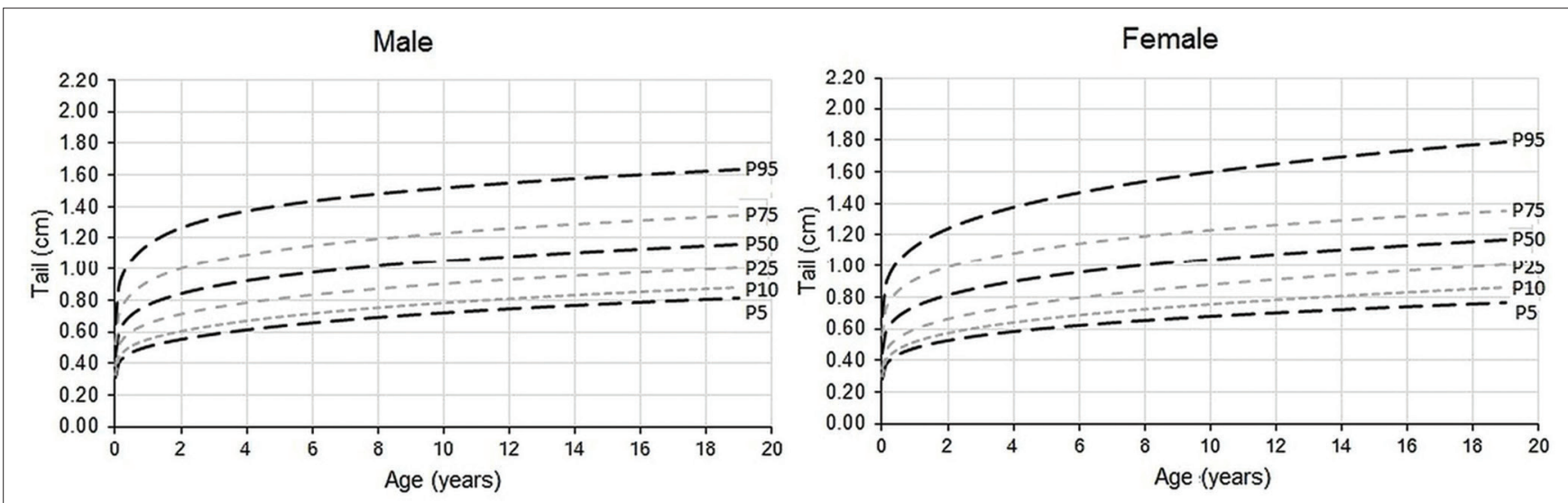

Figure 4: Percentile reference curves for tail of pancreas according to gender in normal Indian children

asymptomatic for the disease can be used to understand the percentile shift in the dimensions of each part and thereby increase the diagnostic strength of pancreatic-related illness.

In summary, this study has established the normal size limits for the pediatric pancreas as determined by the measurement of AP diameter with real-time sonography. Based on this study, the dimensions falling within $5^{\text {th }}$ and $95^{\text {th }}$ percentile along with iso-echogenicity can be regarded as normal. If the dimensions lie outside these limits, along with change of echogenicity, then such cases may be screened further for pancreatic disorders. We believe that a more comprehensive effort is needed to include representative samples from different parts of the country so as to address the biological diversity in pancreatic measurements.

\section{Acknowledgments}

The authors would like to acknowledge the support by Ms. Shubhangi Desai, MDS Bio-Analytics in data analysis and Ms. Trupti Kahate in developing the mobile application for judging the possible deviations in pancreatic dimensions. Contribution by each author is as follows: DSR planned and executed the entire study, DVR carried out statistical analysis of data, VPD provided valuable inputs in the study, and DS contributed in analyzing radiographic data.

\section{Financial support and sponsorship}

Nil.

\section{Conflicts of interest}

There are no conflicts of interest.

\section{References}

1. Caglar V, Kumral B, Uygur R, Alkoc OA, Demirel H, Ozen OA. Study of volume weight and size of normal pancreas, spleen and kidney in adult autopsies. Forensic Med Anat Res 2014;2:63-9.

2. Gupta SP, Tewari GN, Shukla PK. Acute pancreatitis. (A case report). Indian Pediatr 1970;7:294-5.

3. Seigel MJ, Martin KW, Worthington JL. Normal and abnormal pancreas in children: US studies 1. Radiology 1987;165:15-8.

4. Ueda D. Sonographic measurement of the pancreas in children. J Clin Ultrasound 1989;17:417-23.

5. Badea R. Ultrasonography of acute pancreatitis - An essay in images. Rom J Gastroenterol 2005;14:83-9.

6. Bai HX, Lowe ME, Husain SZ. What have we learned about acute pancreatitis in children? J Pediatr Gastroenterol Nutr 2011;52:262-70.

7. Morinville VD, Husain SZ, Bai H, Barth B, Alhosh R, Durie PR, et al. Definitions of pediatric pancreatitis and survey of present clinical practices. J Pediatr Gastroenterol Nutr 2012;55:261-5.

8. Khanna PC, Pruthis: The pancreas. In: Coley BD, Bates DG, Faerber EN, Schulman MH, Kan JH, Lee EY, et al., editors. Caffey's Pediatric Dignostic Imaging. $12^{\text {th }}$ ed., Vol. 2. Philadelphia: Elsevier, Saunders; 2013. p. 995-6.

9. Abu-El-Haija M, Lin TK, Palermo J. Update to the management of pediatric acute pancreatitis: Highlighting areas in need of research. J Pediatr Gastroenterol Nutr 2014;58:689-93.

10. Pant C, Deshpande A, Olyaee M, Anderson MP, Bitar A, Steele MI, et al. Epidemiology of acute pancreatitis in hospitalized children in the United States from 2000-2009. PLoS One 2014;9:e95552.

11. Uc A, Fishman DS. Pancreatic disorders. Pediatr Clin North Am 2017;64:685-706.

12. El-Hodhod MA, Nassar MF, Hetta OA, Gomaa SM. Pancreatic size in protein energy malnutrition: A predictor of nutritional recovery. Eur J Clin Nutr 2005;59:467-73.

13. Chiarelli F, Altobelli E, Verrotti A, Morgese G. Size of pancreas in children and adolescents with type I diabetes mellitus: A study based on ultrasonographic evaluation. Pediatr Res 1994;36:43A.

14. Swobodnik W, Wolf A, Wechsler JG, Kleihauer E, Ditschuneit H. Ultrasound characteristics of the pancreas in children with cystic fibrosis. J Clin Ultrasound 1985;13:469-74.

15. Di Giandomenico V, Filippone A, Basilico R, Spinazzi A, Capani F, Bonomo L, et al. Reproducibility of ultrasound measurement of pancreatic size with new advanced high-resolution dynamic image scanners. J Clin Ultrasound 1993;21:77-86.

16. Pezzilli R, Calculli L. Pancreatic steatosis: Is it related to either obesity or diabetes mellitus? World J Diabetes 2014;5:415-9.

17. Walsh E, Cramer B, Pushpanathan C. Pancreatic echogenicity in premature and newborn infants. Pediatr Radiol 1990;20:323-5.

18. Stasinopoulos DM, Rigby RA. Generalized additive models for location scale and shape (GAMLSS) in R. J Stat Softw 2007;23:1-46. 